\title{
Occupational Attainment And The Earnings Of Native-Born And Foreign-Born Canadians
}

\author{
Najma R. Sharif, Saint Mary's University, Canada
}

\begin{abstract}
The economic performance of immigrants has been studied primarily in terms of entry earnings and how these earnings evolve over time in the host country. The empirical analysis typically revolves around variants of an earnings function, which relates worker earnings to human capital and other individual characteristics. In this literature, the effects of occupational attainment on earnings are typically not modelled mainly because occupation is perceived as just another way of looking at earnings. However, as noted by Chiswick and Miller (2008), amongst others, occupation is the channel through which an individual's human capital translates into earnings. That is, education has both a direct impact on earnings and an indirect one operating through occupational status. Empirical findings for the US and Australia provide support for this view. Our objective in this paper is to extend this analysis to Canada, to assess how the earnings gains from human capital depend upon occupational status for both native-born and immigrant workers, and upon the length of residence of the latter in Canada. This will also shed light on the relative importance of the intra-occupational vis-a-vis inter-occupational mobility of immigrants in realizing earnings gains from education, in the short and longer term. The paper assesses these issues by looking at data drawn from the 2001 Canadian census.
\end{abstract}

Keywords: Native-Born and Foreign-Born Earnings; Schooling; Occupational Choice; Canadian Census Data

\section{INTRODUCTION}

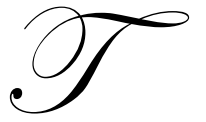

he assimilation of immigrants to host country labour markets has been studied at length by examining various labour market outcomes, such as earnings, labour force participation and occupation. A central idea in the literature has been that, upon entry, immigrants are at a disadvantage since they are not familiar with host country labour markets and, more significantly, because of the difficulty in transferring their human capital skills acquired prior to migration. This disadvantage is magnified to the extent immigrants are not fluent in the host country language. As a result, one might expect that their labour market outcomes are inferior to otherwise similar native born individuals, at least upon entry. For example, they might be unemployed or underemployed, in occupations that do not match their skills, and consequently earn lower wages. On the other hand, there is clearly the positive selectivity of immigrants for labour market success, especially of economic immigrants, so one might also expect that this disadvantage is only temporary; that is, as time passes they are better matched and their labour market outcomes come to match those of similar native born. As noted by Chiswick and Miller (2008), for this to occur, the positive effects alluded to above outweigh the negative effects resulting from the inability to transfer skills acquired in the home country. There is a considerable literature examining the assimilation of foreign-born to host country labour markets - see, for instance, Aydemir and Sweetman (2006), Baker and Benjamin (1994), Ferrer and Riddell (2008), Green (1999), Prescott and Wandschneider (1995), Schaafsma and Sweetman (2001), Sharif and Dar (2007), and Worswick (1996), for a sampling of the Canadian literature.

Although significant work on immigrant success (or the lack of it) has been done in countries that experience large immigrant flows (Canada, the US, Australia, and the UK), further research on the process of 
adjustment by immigrants to host country labour markets is needed to further our understanding of observed labour market outcomes, especially of immigrants belonging to various ethnic groups. In a recent study, using data on adult men in the USA, Chiswick and Miller (2007) argue that insights into the labour market adjustment of immigrants can be gained through estimation of earnings functions that take account of occupational status. These functions that also include controls for occupation shed light on the role that occupation plays as an intermediary between immigrants' human capital skills and their earnings. For instance, Chiswick and Miller (2007) find that nearly 60 per cent of immigrants' earnings gains in the USA can be attributed to inter-occupational earnings differences, with just over 40 per cent to intra-occupational differences, in contrast to 55 and 45 per cent respectively for native-born men.

Chiswick and Miller (2008) obtain similar results for Australia. Our aim in this paper is to extend the analysis to Canada. The rest of the paper is organized as follows. In Section II, we discuss the methodology and data. Our findings are presented and analysed in Section III. Section IV concludes with a summary of the major findings.

\section{EARNINGS, SCHOOLING \& OCCUPATION: MODELS \& ESTIMATION STRATEGY}

The analysis of the returns to human capital characteristics is typically conducted by estimating a standard Mincer-type earnings function model of the following form:

$w_{i}=\boldsymbol{\beta}^{\prime} x_{i}+u_{i}$

where $w$ is the natural log of an individual's wage (earnings), $\boldsymbol{x}$ is a vector of human capital and other factors that cause earnings to differ across individuals, $\boldsymbol{\beta}$ is a vector of parameters, and $u$ is the random disturbance term. Human capital characteristics usually considered include an individual's schooling, labour market experience, and for foreign-born workers, their language ability and length of residence in the host country. Additional variables to control for the effects of location, marital status and sex are also often included. The effects of occupational attainment on earnings are, however, not modelled in the earnings function mainly because occupation is perceived as just another way of looking at earnings. However, as noted by Chiswick and Miller (2007), amongst others, it is an individual's occupation that is the channel through which an individual's human capital translates into earnings. In other words, education has both a direct impact on earnings and an indirect one operating through occupational status. In order to separate these impacts, we employ, following Chiswick and Miller (2007, 2008), the econometric methodology underlying the analysis of omitted variable bias.

If occupational variables belong to the model, then equation (1) is mis-pecified and the estimators of the returns to schooling and other human capital variables, will be biased. Nevertheless, (1) provides a useful benchmark to study the indirect and direct impacts of human capital variables on earnings.

Consider, for instance, estimating the direct and indirect impact of schooling on earnings. If we estimate (1), then the coefficient of the schooling variable will capture both the direct impact of schooling on earnings (holding occupation constant) as well its indirect impact via occupational status. The former represents the return to schooling within an occupation (intra-occupational gains), while the latter reflects the gains in wages resulting from occupational mobility (inter-occupational gains). Of course, the estimate of the schooling parameter in (1) does not allow us to separate these two effects. However, if we estimate (1) by augmenting it with occupational variables, then the schooling parameter would correctly measure the direct impact (holding occupation constant), so that the difference between the estimates of the schooling parameter in the augmented model and the benchmark model would measure the indirect effect. This can be seen by noting that the estimator of the schooling parameter in (1) let us call this $b_{j}$ - can be shown to be:

$b_{j}=b_{j}^{\wedge}+\Sigma a_{k} d_{k},(\mathrm{j}$ not equal to $\mathrm{k})$

where $b^{\wedge}$ is the estimator of the schooling parameter in the augmented model (and measures the direct impact alluded to above), and the second term measures the indirect impact on earnings through occupational status. Specifically, $a_{k}$ is the estimated impact of the $\mathrm{k}^{\text {th }}$ occupational variable on earnings in the augmented model, and $d_{k}$ is the coefficient of schooling in an auxiliary regression of the $\mathrm{k}^{\text {th }}$ occupational variable on schooling and all other 
variables included in the benchmark model (1). Of course, a similar breakdown of direct and indirect impacts can be made for other human capital variables in the earnings function. As a consequence, a comparison of the estimates in the equation with the occupation variables with estimates from the benchmark model (1) provides information on the effect of these variables on earnings through intra- and inter-occupational change. Specifically, $\left(b_{j}-b_{j}^{\wedge}\right) 100$ is the percentage point payoff to schooling that can be attributed to its effect on occupational status. This methodology is used to study native-born-foreign-born earnings in Australia and the US by Chiswick and Miller (2008) and Chiswick and Miller (2007) respectively, and is applied in this paper to native born and foreign born Canadians using data drawn from the public-use 2001 Canadian census files for individuals. Our sample is confined to full-time male workers, aged 25-64 years, who reported positive earnings in the census year. This facilitates comparison with the aforementioned US and Australian studies.

We estimate both the benchmark model (1), and the augmented model that includes occupational variables for native-born and foreign-born males. Following common practise, the earnings function employed in this paper relates the natural logarithm of an individual's weekly wages to his human capital and other individual characteristics. The two main human capital variables are education, measured in years of schooling completed, and potential labour market experience, with linear and quadratic terms, measured by an individual's age less schooling less 6. Note that since we also control for the length of residence of the foreign-born in Canada, the labour market experience coefficients can be interpreted as measuring the payoff to pre-immigration experience. For the foreignborn, language ability is likely to be an important determinant of the quality of their human capital in Canada. The language ability variable is a binary variable, with default case being a foreign-born individual who knows at least one official language. The final variable that would affect human capital is the length of residence of the foreignborn in Canada. One would expect that as length of residence in increases, immigrants' human capital becomes more suited to the Canadian labour market, and this is reflected in their occupational choices. To assess how the length of residence in Canada impacts on wages, we introduce a number of binary variables in the foreign-born earnings function. Specifically, we define four immigrant cohorts, reflecting the vintage of the foreign-born. These cohorts are as follows. We define "new" immigrants as those who arrived in Canada between 1996-2001 inclusive. The older cohorts are then defined as those arriving between 1991-1995, those arriving between 1986-1990 and those who arrived prior to 1986. We introduce these as binary variables (the pre-1986 cohort being the default group). We also controlled for person's location and marital status. Specifically, the location variable is a binary variable equal to 1 if the person resided in a census metropolitan area (CMA), and zero otherwise, while the marital status is also a binary variable, equal to one if an individual is married, and zero otherwise.

In the augmented regression, we add to the benchmark model (1) a set binary variables that flag an individual's occupation. The occupations used as those based on the 2001 National Occupational Classification for Statistics for which data are available in the 2001 Census files. These data classify occupations into 25 groups, so that the augmented model contains 24 binary variables, each equal to one if an individual belongs in a group, and zero otherwise. The default group is that consisting of individuals in senior management positions.

\section{ANALYSIS OF THE RESULTS}

We begin with a discussion of the main features of our estimated earnings functions for native-born and foreign-born males. These are reported in Table 1 for both the benchmark and augmented functions for native-born and foreign-born males. The coefficients in all regressions have the expected signs and, with one exception, are statistically significant at the 5 percent level or less. For both the benchmark and augmented models, a comparison of the native-born and foreign-born regressions shows that the payoffs to schooling and labour market experience are both higher for the former, which is in line with expectations and with findings for the US and Australia [Chiswick (2007), 2008)]. One difference is that native-born CMA residents earn more while foreign-born residents earn less than their non-CMA counterparts. However, the foreign-born coefficient is not statistically significant.

For the foreign-born, not being able to speak at least one official language has a strong negative impact on earnings, and it is also evident that foreign-born cohorts that are new to Canada earn significantly less than older cohorts. As expected then, foreign-born males have poorer wage outcomes when they are new to Canada; as well, the payoffs to schooling and to labour market experience are also inferior to those of native-born males. 
Of greater interest is the question of how the payoffs to schooling (and other human capital variables) are affected by including controls for occupation in the earnings function. Since the augmented equation allows us to hold occupation constant, the coefficients of schooling and other variables in the model, are measures of the impact on intra-occupational earnings mobility - that is, the direct impact of these variables on earnings. These results are summarized in Table 2. First of all, note that controlling for occupation, reduces the payoffs to schooling for both native and foreign born males - from 7 percent to 5.1 percent, a 27 percent reduction for the native-born, and from 5.7 percent to just 3 percent, a significantly larger decline of 47 percent for the foreign-born. These numbers mean that about 47 percent and 27 percent of the return to additional schooling for the foreign-born and native-born males respectively is due to entry into higher paying occupations - that is, the indirect impact of schooling on earnings through occupational mobility. The rest of the payoffs measure the direct impact of additional schooling on earnings within occupations. In other words, intra-occupational earnings mobility plays a relatively more important role in realizing the gains from schooling both groups; yet, its relative importance varies substantially between these two groups. Thus, about 73 percent and 53 percent of the payoff to schooling for the native-born and foreign-born respectively are realized through upward mobility within the same occupation, while the corresponding estimates are 77 percent and 60 percent for the US, and 76 percent and 62 percent for Australia - see Chiswick and Miller (2007, 2008). Thus, the findings for all three countries paint a similar picture - that, inter-occupational mobility is much more important for the foreign-born than it is for the native-born in realizing the gains from schooling.

Table 1

Estimated Earnings Functions: Native-Born and Foreign-Born Males

\begin{tabular}{|c|c|c|c|c|}
\hline \multirow[b]{2}{*}{ Variables } & \multicolumn{2}{|c|}{ Native-Born } & \multicolumn{2}{|c|}{ Foreign-Born } \\
\hline & $\begin{array}{c}\text { Benchmark } \\
\text { model }\end{array}$ & $\begin{array}{c}\text { Augmented } \\
\text { model }\end{array}$ & $\begin{array}{c}\text { Benchmark } \\
\text { model }\end{array}$ & $\begin{array}{c}\text { Augmented } \\
\text { Model }\end{array}$ \\
\hline Constant & $\begin{array}{c}5.068 \\
(280.0) \\
\end{array}$ & $\begin{array}{c}5.804 \\
(218.6) \\
\end{array}$ & $\begin{array}{l}5.3720 \\
(139.3) \\
\end{array}$ & $\begin{array}{c}6.455 \\
(106.1) \\
\end{array}$ \\
\hline Education & $\begin{array}{l}0.0702 \\
(70.22) \\
\end{array}$ & $\begin{array}{l}0.0505 \\
(43.95) \\
\end{array}$ & $\begin{array}{l}0.0566 \\
(29.28) \\
\end{array}$ & $\begin{array}{l}0.0304 \\
(14.22) \\
\end{array}$ \\
\hline Experience & $\begin{array}{l}0.0327 \\
(35.65)\end{array}$ & $\begin{array}{l}0.0317 \\
(35.06)\end{array}$ & $\begin{array}{l}0.0076 \\
(3.733)\end{array}$ & $\begin{array}{l}0.0118 \\
(5.963)\end{array}$ \\
\hline Experience squared/1000 & $\begin{array}{l}-0.4611 \\
(-23.09)\end{array}$ & $\begin{array}{c}0.4686 \\
(-23.83)\end{array}$ & $\begin{array}{l}-0.0731 \\
(-1.784)\end{array}$ & $\begin{array}{l}-0.1637 \\
(-4.099)\end{array}$ \\
\hline CMA resident & $\begin{array}{l}0.1144 \\
(22.94) \\
\end{array}$ & $\begin{array}{l}0.1023 \\
(20.59) \\
\end{array}$ & $\begin{array}{l}-0.0198 \\
(-1.134) \\
\end{array}$ & $\begin{array}{l}-0.0275 \\
(-1.562) \\
\end{array}$ \\
\hline Married & $\begin{array}{l}0.1993 \\
(34.03)\end{array}$ & $\begin{array}{l}0.1628 \\
(28.06)\end{array}$ & $\begin{array}{l}0.1229 \\
(9.125)\end{array}$ & $\begin{array}{l}0.0961 \\
(7.337)\end{array}$ \\
\hline Language proficiency & No & No & $\begin{array}{l}-0.2148 \\
(-4.850) \\
\end{array}$ & $\begin{array}{l}-0.1609 \\
(-3.679) \\
\end{array}$ \\
\hline $\begin{array}{l}\text { 1996-2001 } \\
\text { Arrival }\end{array}$ & No & No & $\begin{array}{l}-0.3592 \\
(19.75) \\
\end{array}$ & $\begin{array}{c}-0.3343 \\
(18.80) \\
\end{array}$ \\
\hline $\begin{array}{l}\text { 1991-1995 } \\
\text { Arrival }\end{array}$ & No & No & $\begin{array}{l}-0.3084 \\
(-18.51) \\
\end{array}$ & $\begin{array}{l}-0.2702 \\
(-16.70) \\
\end{array}$ \\
\hline $\begin{array}{l}\text { 1986-1990 } \\
\text { Arrival }\end{array}$ & No & No & $\begin{array}{l}-0.2160 \\
(-12.69) \\
\end{array}$ & $\begin{array}{l}-0.1803 \\
(-10.77) \\
\end{array}$ \\
\hline Occupation & No & Yes & No & Yes \\
\hline F-statistic & 2041 & 521.6 & 251.9 & 118.8 \\
\hline Adjusted $\mathrm{R}^{2}$ & 0.091 & 0.129 & 0.076 & 0.125 \\
\hline Sample size & 102,232 & 102,232 & 27,308 & 27,308 \\
\hline
\end{tabular}

Notes: The numbers in parentheses are heteroscedasticity-consistent $t$ statistics;

Yes indicates that the variable is included in the model, No implies that it has not;

Occupation signifies 24 dichotomous variables controlling for occupation.

Looking next at labour market experience, note first that the payoffs to this attribute of human capital are significantly lower for foreign-born males, evaluated at 10 and 20 years of labour market experience, in both the benchmark and augmented models. This is not surprising since Canadian labour markets can be expected to devalue experience acquired abroad given the imperfect transferability of skills. However, controlling for occupation leads to 
only a small decrease of the order of 7-8 percent in the payoff to labour market experience for native-born males. In other words, upwards of 90 percent of the gain from labour market experience for the native-born is intraoccupational. This suggests that inter-occupational mobility plays a minor role in realizing the gains from labour market experience for the native-born. As well, it might indicate that pre-labour market characteristics play an important role in determining occupational status, as noted by Chiswick and Miller (2007), whose findings for the US are similar.

The picture is clearly different for the foreign-born. Thus, in contrast to the native-born, allowing for occupation raises the return from labour market experience by 39 percent and 13 percent at 10 and 20 years of experience respectively. The corresponding estimates are 41 percent and 21 percent for US immigrants, and 32 percent and 10 percent for non-English speaking Australian immigrants. Since the labour market experience coefficient measures the impact of pre-migration experience, these numbers suggest that pre-immigration experience is likely associated with foreign-born males entering relatively low earnings occupations in Canada. This is in line with findings that initially immigrants in Canada enter into low-paying occupations because of the difficulty of transferring their skills and the lack of familiarity of the host country labour market - see, for instance, Green (1999).

Table 2 also shows that the disadvantage associated with a lack of language proficiency is high for the foreign-born. A foreign-born male who does not know at least one language (English or French), is expected to earn about 21.5 percent less than one does not have this difficulty, in the benchmark model. However, once we allow for occupational controls in the model, this disadvantage falls to 16 percent, which is an increase of about 25 percent. This suggests that the language disadvantage within an occupation is high, accounting for about 75 percent of the total earnings disadvantage, with an additional 25 percent resulting from the adverse impact of not knowing an official language on occupational status. This could be because those with a language disadvantage, especially among some of the ethnic immigrant groups, choose occupations that does not emphasize language ability as much (for example, in ethnic labour markets), and these may be associated with lower wages. Thus, the benchmark model, which does not allow for this adverse inter-occupational effect, understates the earnings loss resulting from a language disadvantage.

Table 2

Estimated Payoffs to Schooling and Other Characteristics: 2001 Census

\begin{tabular}{|c|c|c|c|}
\hline \multicolumn{1}{|c|}{ Variable } & Payoffs from Earnings Functions (\%) & $\begin{array}{c}\text { Model with } \\
\text { Occupational Controls }\end{array}$ & $\begin{array}{c}\text { Percentage } \\
\text { change }\end{array}$ \\
\hline Native-Born & $\begin{array}{c}\text { Benchmark } \\
\text { model }\end{array}$ & 5.1 & -27.1 \\
\hline Schooling & 7.0 & & -8.3 \\
\hline Experience & & 2.2 & -7.1 \\
\hline - 10 years & 2.4 & 1.3 & \\
\hline - 20 years & 1.4 & & -47.4 \\
\hline Foreign-Born & & 3.0 & \\
\hline Schooling & 5.7 & & 39.3 \\
\hline Experience & & 0.85 & 12.8 \\
\hline -10 years & 0.61 & 0.53 & 25.1 \\
\hline - 20 years & 0.47 & -16.1 & \\
\hline Language proficiency & -21.5 & & \\
\hline Migration period & & -33.4 & \\
\hline $1996-2001$ & -35.9 & -27.0 & 12.3 \\
\hline $1990-1995$ & -30.8 & -18.0 & \\
\hline $1986-1990$ & -21.6 & & \\
\hline
\end{tabular}

Turning next to the immigrant duration variables, which measure post-migration experience, we note that in comparison to the "old" immigrants - that is, those who migrated before 1986 - all other foreign-born cohorts earn significantly less in both the benchmark and augmented equations. As well, this negative impact is larger, the 
more recent the foreign-born cohort. This suggests that, regardless of the occupation, recent foreign-born immigrants have a much more difficult time in Canadian labour markets, again because of the difficulty in transferring their skills acquired prior to migration. Both equations suggest that this disadvantage diminishes with time. Despite this, it is worth noting that the earnings disadvantage of newer immigrants relative to the pre 1986 group moderates once we allow for occupational effects, but this reduction is smallest among the newer groups -7 percent for those who migrated between 1996-2001 and almost 17 percent for those who came during 1986-1990. In any event, the occupational effects are relatively small, implying that newer immigrants have a large wage disadvantage relative to established immigrants, regardless of occupation.

\section{CONCLUSIONS}

This paper empirically examined importance of occupation as an intermediary between human capital and earnings for full-time, native and foreign born male workers in Canada. This was done by estimating the direct (intra-occupation) and indirect (inter-occupation) impact of human capital variables from earnings functions, which in turn were estimated from data drawn from the 2001 Canadian census. Our estimates show that, first, the gain from schooling is clearly lower for the foreign born and that this disadvantage is even bigger once occupation is taken into account. As well, about 27 percent and 47 percent of the gains from schooling come through entry into higher paying occupations for native-born and foreign-born workers respectively. Thus, the foreign born rely much more on occupational change to realize gains from schooling. This finding is in line with estimates obtained for Australia and the US by Chiswick and Miller (2007, 2008). Secondly, occupation has only a modest impact on the payoff to labour market experience for the native-born. For the foreign-born, however, pre-immigration labour market experience has very low direct gains (under 1 percent); yet, allowing for occupation actually raises the payoff to pre-migration experience. This could mean that foreign-born enter into low-paying occupations because of the imperfect transferability of human capital. Again, similar results were obtained by Chiswick and Miller (2007, 2008) for Australian and US immigrants. Thirdly, there is a strong earnings disadvantage for those who do not know at least one official language. This adverse effect is primarily felt via the direct effect on earnings within an occupations (about $75 \%$ ), with the adverse impact on occupational attainment adding $25 \%$ to that disadvantage. Fourthly, there is a large wage advantage for those who have been in Canada the longest relative to newer immigrants, but most of this gain is achieved within occupations - that is, through intra-occupation earnings mobility - once the passage of time has enabled immigrants overcome initial disadvantages in the Canadian labour market.

\section{AUTHOR INFORMATION}

Najma R. Sharif is Associate Professor in the Department of Economics in the Sobey School of Business at Saint Mary's University, Halifax, Canada. She obtained her Ph.D in Economics from McMaster University in 1992. Her current research interests are focussed on the labour market outcomes of immigrants. She teaches courses in Development Economics, Social Cost-Benefit Analysis, and Monetary Economics, in addition to introductory theory courses in Economics. E-mail: najma.sharif@ smu.ca

\section{REFERENCES}

1. Aydemir, A. and A. Sweetman (2006), "First and Second-Generational Educational Attainment and Labor Market Outcomes: A Comparison of the United States and Canada, IZA Discussion Paper 2298, Institute for the Study of Labour, Bonn, Germany.

2. Baker, M. and Benjamin, D. (1994), "The Performance of Immigrants in the Canadian Labour Market", Journal of Labour Economics, 12, 369-405.

3. Chiswick, Barry R. and Paul W. Miller (2008), "Occupational Attainment and Immigrant Economic Progress in Australia", The Economic Record, 84 (Special Issue), S45-S556.

4. Chiswick, Barry R. and Paul W. Miller (2007), "Earnings and Occupational Attainment: Immigrants and the Native Born", IZA Discussion Paper 2676, Institute for the Study of Labour, Bonn, Germany.

5. Ferrer, Ana and Riddell, W. Craig, (2008), "Education, Credentials, and Immigrant Earnings", Canadian Journal of Economics, 41(1), 186-216.

6. Green, David A. (1999), "Immigrant Occupational Attainment: Assimilation and Mobility over Time," Journal of Labor Economics, 17(1), 49-79. 
7. Hum, D. and Simpson, W., (2004)," Economic Integration of Immigrants to Canada: A Short Survey", Canadian Journal of Urban Research, 13, 46-61.

8. Prescott David and Wandschneider, B., (1995), "The Assimilation of Immigrants in the Canadian Labour Market: 1981-1990”, Discussion Paper No. 1995-11, University of Guelph, Guelph, Canada.

9. Schaafsma, Joseph and Sweetman, Arthur, (2001). "Immigrant Earnings: Age at Immigration Matters", Canadian Journal of Economics, Vol. 34, No.4, 1066-1099.

10. Sharif, Najma R., and Atul Dar (2007), "An Empirical Investigation of the Impact of Imperfect Information on Wages in Canada," Review of Applied Economics, 3:1-2, 137-155.

11. Worswick, C., (1996), "Immigrant Families in the Canadian Labour Market", Canadian Public Policy, 12, 378-396. 


\section{NOTES}

